\title{
Miradoux (canton de) (Gers)
}

Prospections

\section{Marie-Line Mondin}

\section{(2) OpenEdition}

Journals

Édition électronique

URL : http://journals.openedition.org/adlfi/10832

ISSN : 2114-0502

Éditeur

Ministère de la culture

Référence électronique

Marie-Line Mondin, «Miradoux (canton de) (Gers) », ADLFI. Archéologie de la France - Informations [En ligne], Midi-Pyrénées, mis en ligne le 01 mars 1997, consulté le 20 avril 2019. URL : http:// journals.openedition.org/adlfi/10832

Ce document a été généré automatiquement le 20 avril 2019.

(c) Ministère de la Culture et de la Communication, CNRS 


\title{
Miradoux (canton de) (Gers)
}

\author{
Prospections
}

\author{
Marie-Line Mondin
}

Date de l'opération : 1991 (PR)

Inventeur(s) : Mondin M.-L

1 Dans le cadre d'un mémoire de maîtrise portant sur l'occupation du sol au Moyen Âge, il a été possible de recenser plusieurs sites antiques et du Haut Moyen Âge restés, pour la plupart, inédits ou absents de toutes références bibliographiques récentes mis à part ceux déjà signalés par J. Lapart dans sa thèse sur les cités d'Auch et d'Éauze (Lapart, 1985).

2 En dehors de l'établissement gallo-romain de Lucy ou Lussy (Gallia, 1966 : 437) déjà connu à Plieux, des prospections non systématiques ont révélé la présence de structures bâties et de mobilier gallo-romain marquant la présence d'établissements de nature indéterminée: Flamarens; Miradoux, Capdeville et le Tuco; Plieux, La BordevieilleLasmothes; Sempesserre, Bidot (Lapart 1985), parfois associés à des nécropoles en sarcophage.

3 Trois mottes castrales (Castet-Arrouy, Gachepouy ; Flamarens, La Mothe ; Miradoux, La Garenne), une tour-salle du XIII $\mathrm{s}$. (Plieux, La Rouquette), une maison-forte (Sempesserre, Las Martres), quatre châteaux gascons (Castet-Arrouy, Gachepouy; Gimbrède, Rouillac; Plieux et Sainte-Mère) dont les deux derniers peuvent être datés du $\mathrm{XIII}^{\mathrm{e}} \mathrm{s}$. et du XIV ${ }^{\mathrm{e}}$ s., ont fait l'objet d'études à partir des sources écrites et ont, pour quelques-uns, révélé la présence presque constante de sépultures (terre libre et sarcophage) dont la chronologie reste à préciser.

4 Hormis un seul village écclésial supposé à Saint-Antoine, Saint-Martin, la lecture des sources écrites, des documents cadastraux et des Pouillés des provinces d'Auch, de Narbonne et de Toulouse à permis de dénombrer cinq castelnaux (Flamarens, Miradoux, Plieux, Sainte-Mère, Sempesserre) ainsi que deux villages de commanderie (Gimbrède et Saint-Antoine). 
INDEX

Index chronologique : Antiquité romaine, Moyen Âge*

Index géographique : Midi-Pyrénées, Gers (32), Miradoux

operation Prospection (PR) 